\title{
Correction to: Predictors of abatacept retention over 2 years in patients with rheumatoid arthritis: results from the real-world ACTION study
}

\author{
Rieke Alten ${ }^{1} \cdot$ Xavier Mariette $^{2} \cdot$ Hanns-Martin Lorenz ${ }^{3} \cdot$ Hubert Nüßlein $^{4} \cdot$ Mauro Galeazzi $^{5} \cdot$ Federico Navarro $^{6}$. \\ Melanie Chartier ${ }^{7}$. Julia Heitzmann ${ }^{8}$. Coralie Poncet ${ }^{9}$. Christiane Rauch $^{10}$ • Manuela Le Bars ${ }^{11,12}$
}

Published online: 11 April 2019

(C) International League of Associations for Rheumatology (ILAR) 2019

\section{Correction to: Clinical Rheumatology https://doi.org/10.1007/s10067-019-04449-w}

The article listed above was initially published with incorrect copyright information.

Upon publication of this Correction, the copyright of this article changed to "The Author(s)".

The original article has been corrected.

Publisher's note Springer Nature remains neutral with regard to jurisdictional claims in published maps and institutional affiliations.

The online version of the original article can be found at https://doi.org/ 10.1007/s10067-019-04449-w

Rieke Alten

rieke.alten@schlosspark-klinik.de

1 Department of Internal Medicine, Rheumatology, Clinical Immunology, and Osteology, Schlosspark-Klinik University Medicine Berlin, Heubnerweg 2, 14059 Berlin, Germany

2 Department of Rheumatology, Université Paris-Sud, Paris, France

3 Department of Rheumatology, University Hospital, Heidelberg, Germany

4 Department of Internal Medicine and Rheumatology, University of Erlangen-Nuremberg, Nuremberg, Germany

5 Department of Medical Sciences, Surgery, and Neuroscience, University of Siena, Siena, Italy
6 Department of Rheumatology, Hospital Universitario Virgen Macarena, Seville, Spain

7 Marketed Product Late Stage Operation Department, Bristol-Myers Squibb, Rueil-Malmaison, France

8 Excelya, Boulogne-Billancourt, France

9 Docs International, Issy-les-Moulineaux, France

10 Department of Immunoscience, Bristol-Myers Squibb, Munich, Germany

11 Speciality Development Immunology, Bristol-Myers Squibb, Rueil-Malmaison, France

12 Present address: Janssen-Cilag European Medical Affairs Immunology-Gastroenterology, 92787 Issy-les-Moulineaux, France 